\title{
Inhibitory Activity of Combretum zeyheri and its S9 Metabolites against Escherichia coli, Bacillus subtilis and Candida albicans
}

\author{
Charlotte Masengu' ${ }^{1}$, Faith Zimba1, Rumbidzai Mangoyi ${ }^{2}$ and Stanley Mukanganyama ${ }^{2 *}$ \\ ${ }^{1}$ School of Pharmacy, College of Health Sciences, University of Zimbabwe, Mt. Pleasant, Harare, Zimbabwe \\ ${ }^{2}$ Department of Biochemistry, University of Zimbabwe, Mt. Pleasant, Harare, Zimbabwe
}

\begin{abstract}
Medicinal plants are therapeutic resources used by traditional population for health care, thus, it is important to evaluate the mechanism of action of herbal plants so as to validate their efficacy and avoid possible toxic effects. The water and methanol leaf extracts of Combretum zeyheri, medicinal plant from Zimbabwe were screened for antibacterial activity against Escherichia Coli and Bacillus subtilis using the agar disc diffusion method. Minimum inhibitory concentration (MIC) and minimum bactericidal concentration (MBC) values of the plant extracts were determined using the broth dilution method. Drug transport assays were conducted to test the potential of plant extracts as inhibitors of drug efflux using in Rhodamine 6G. The effect of Combretum zeyheri plant S9 metabolites on growth of Candida albicans was investigated using S9 fractions from 8 week old male Sprague-Dawley rats. Results showed that the plant extract had antibacterial activity against $E$. coli and $B$. subtilis, with the aqueous extract exhibiting a greater inhibition of growth than the methanol extract. The plant extract also showed inhibitory effects on drug efflux in all the three organisms suggesting that the antimicrobial actions could partly be due to inhibition of drug efflux pumps. The S9 metabolites of $C$. zeyheri also had an inhibitory effect on growth of $C$. albicans, suggesting they may be inhibitors of the growth of Candida albicans in vivo. Combretum zeyheri, therefore, has significant antimicrobial activity and, therefore, has a basis for its use in traditional herbal medications for the treatment of a broad range of microbial infections. The antifungal effects may be mediated via both parent extracts and their metabolites.
\end{abstract}

Keywords: Plant metabolites; E. coli; B. subtilis; C. albicans; Drug efflux, Sprague-dawley rats; Antibacterial; Antifungal; Drug metabolism

Abbreviations: MIC: Minimum Inhibitory Concentration; MBC: Minimum Bactericidal Concentration; UDPGA: Uridine Diphosphate Glucuronic Acid; NADPH: Nicotinamide Adenine Dinucleotide Phosphate Reduced; SDA: Sabouraud Dextrose Agar; ATCC: American Type Culture Cell; CFU: Colon Forming Units; GSH: Glutathione; GST: Glutathione-S-Transferase; CYP: Cytochrome P450; PBS: Phosphate Buffered Saline; R6G: Rhodamine

\section{Introduction}

Microbial organisms cause a number of infections which include pneumonia, meningitis, tuberculosis, whooping cough, trachoma, tetanus, diphtheria, urinary tract infections, diarrhea, peptic ulcer, gonorrhea, syphilis, bubonic plague, cholera and septicemia [1]. The development of antibiotics in the 1940s offered mankind a powerful tool against bacterial infections [2], however, because of the widespread and sometimes inappropriate use of antibiotics, antibiotic resistant strains of bacteria are emerging. With this emergence, particularly of bacteria expressing multidrug resistance (MDR), there is an urgent need for new drugs to treat these infectious diseases. Many of the currently available antibiotics have undesirable side effects, lead to rapid development of resistance or are ineffective against new or re-emerging bacterial species [3]. Membrane-based efflux pump (EP) systems play an important role in bacterial pathogenicity and antimicrobial resistance in bacteria by decreasing intracellular drug concentrations used in a clinical setting thereby preventing the compounds from reaching their intended targets. A single pump can provide bacteria with resistance to a wide array of chemically and structurally diverse compounds [4]. Therefore, it is important to explore new Effective bacterial EP inhibitors (EPIs) for bacteria. Effective bacterial EP inhibitors should decrease the intrinsic resistance of bacteria to antibiotics, reverse acquired resistance and reduce the frequency of the emergence of newly resistant mutant strains [5].
Plants have been shown to contain more compounds than chemists can synthesize and have served as a source of new drugs, pharmaceutical products and starting materials for synthesis of many known drugs [6]. Phytomedicines are a major component of traditional system of healing in developing countries which have been an integral part of their history and culture. They are also becoming the integrative healthcare system of industrialized nations where they are referred to as alternative and complementary medicines [7].

At least twenty four species of Combretum plant family are well known in African traditional medicine. They are used for the treatment of a variety of ailments and diseases, ranging from scorpion and snake bites, mental problems, heart and worm remedies to fever and microbial infections [8]. Combretacae species have been used for the relief of a number of ailments amongst which are fever, headaches, gallstones, diarrhoea, dysentery gastric ulcers, nosebleeds, sore throats, colds, chest coughs, pneumonia, conjunctivitis, dysmenorrhoea, infertility in women, venereal diseases including syphilis, toothache, heart diseases, cleansing the urinary system, backache, jaundice, stomach and gastric problems and others [9]. This study focused on Combretum zeyheri, a medium sized tree found from the coast to the Midlands in the Eastern

*Corresponding author: Dr. Stanley Mukanganyama, Biomolecular Interactions Analyses Group, Department of Biochemistry, University of Zimbabwe, P.O Box MP 167, Mt. Pleasant, Harare, Zimbabwe, Tel: 263-4-2917638; E-mail smukanganyama@medic.uz.ac.zw, smukanganyama01@gmail.com

Received March 04, 2014; Accepted May 05, 2014; Published May 09, 2014

Citation: Masengu C, Zimba F, Mangoyi R, Mukanganyama S (2014) Inhibitory Activity of Combretum zeyheri and its S9 Metabolites against Escherichia coli, Bacillus subtilis and Candida albicans. J Microb Biochem Technol 6: 228-235. doi:10.4172/1948-5948.1000149

Copyright: (c) 2014 Masengu C, et al. This is an open-access article distributed under the terms of the Creative Commons Attribution License, which permits unrestricted use, distribution, and reproduction in any medium, provided the original author and source are credited 
region of Zimbabwe [10], and has been reported to have antifungal effects on growth of C. albicans [11].

Candida albicans is an opportunistic pathogen responsible for various non-life-threatening infections, such as oral thrush and vaginitis, and accounts for the majority of all Candida infections [12]. The fungus can travel through the bloodstream and affect several other organs such as the heart valves [13]. This pathogen is a major cause of morbidity and mortality in bloodstream infections, especially in immunosuppresed individuals [14]. E. coli is a gram negative rod shaped bacterium commonly found in the lower intestine of warmblooded organisms and causes many bacterial infections including cholecystitis, bacteremia, cholangitis, urinary tract infection and travelers' diarrhea [15]. E. coli is one of the gram negative bacteria that can easily be grown in the lab and mostly used as test organism. Bacilli cause many infections such as meningitis, ear infections, urinary tract infections and septicemia. The infections caused by Bacilli mostly occur as secondary infections in immunodeficiency hosts and may exacerbate previous infection by producing tissue damaging toxins or metabolites that interfere with treatment [16]. Bacillus subtilis is a gram-positive, catalase positive bacterium commonly found in soil. It is used as a model organism for Bacillus anthracis.

Regardless of the great progress in medicinal chemistry, the development of novel drugs has become more and more difficult partly due to the fact that good drugs for major diseases are available and developing better ones that are active at the same site and not expensive has become increasingly difficult [17]. The screening of plant extracts and plant products for antimicrobial activity has shown that higher plants represent a potential source of new anti-infective agents. There is an emergence of drug-resistant strains of fungi and bacteria because of widespread and sometimes inappropriate use of antibiotics and antifungal agents in HIV treatment $[18,19]$. There is need for the discovery of new lead compounds that may help in the fight against these resistant strains of bacteria but these medications should also have minimum side effects as most of the current drugs have undesirable side effects. The objective of this study, therefore, was to determine whether the action of C. zeyheri extracts on C. albicans was due to the parent extract or metabolites and also to determine if the antibacterial action was due to inhibition of efflux in $E$. coli and $B$. subtilis.

\section{Materials and Methods}

\section{Chemicals and test organisms}

All chemicals used in this study including nutrient agar, Sabouraud dextrose agar (SDA), miconazole, ethanol and dimethyl sulphoxide were purchased from SIGMA-ALDRICH CHEMICAL CO. (St Louis, MO, USA), and were of analytical reagent grade. Escherichia Coli (ATCC 11229), Bacillus subtilis (ATCC 6633) and Candida albicans (ATCC 10231) were a kind gift from Dr. K. Marobela (Department of Biological Sciences, University of Botswana). All strains were maintained as stock strains in 50\% glycerol in Eppendorf microtubes and kept at $-30^{\circ} \mathrm{C}$ until use. Bacteria were grown in nutrient broth at $37^{\circ} \mathrm{C}$ for $24 \mathrm{~h}$ and adjusted to a concentration of $1 \times 10^{6}$ colony forming units per $\mathrm{ml}(\mathrm{CFU} / \mathrm{ml})$. C. albicans was cultured onto SDA plate and incubated overnight at $37^{\circ} \mathrm{C}$. A single colony was then cultured in SDB at $37^{\circ} \mathrm{C}$ overnight. The density of the fungal culture required for the test was adjusted to $1 \times 10^{6}$ colony forming units $/ \mathrm{ml}(\mathrm{CFU} / \mathrm{ml})$.

\section{Plant collection and extraction}

Combretum zeyheri leaves were collected from Norton
(Mashonaland West, Zimbabwe). The plant was classified by Mr. Chris Chapano, a taxonomist at the National Botanic Gardens, (Harare, Zimbabwe). Herbarium sample voucher number (N6E7) was kept at the Department of Biochemistry, University of Zimbabwe. The preparation of plant extracts was described previously [20]. Briefly, the plant sample was ground in a two-speed blender (COLE PARMER INSTRUMENT CO., Vernon Hills, USA). Each sample was individually extracted by weighing an aliquot of $2 \mathrm{~g}$ of finely ground plant material and extracting with $10 \mathrm{ml}$ of solvents, methanol and water in test tubes. Extracts were filtered through fine cloth and then through 0.45 $\mu \mathrm{m}$ pore size corning syringe filters (SIGMA ALDRICH, Germany). The filtrates were decanted into pre-weighed labeled containers. The solvent was removed under a stream of air in a fume cupboard at room temperature. The amount of solid extract was weighed and recorded.

\section{Determination of antibacterial activities by agar diffusion method}

The disc diffusion method for antibacterial susceptibility testing was carried out according to the standard method to assess the presence of antibacterial activities of the plant extracts [21]. Combretum zeyheri water or methanol extracts were screened for antibacterial and activities against bacterial species (Escherichia Coli, and Bacillus subtilis). Nutrient agar mixed with bacteria at a concentration of $1 \times 10^{6} \mathrm{cfu} / \mathrm{ml}$ was poured in Petri dishes and allowed to cool. The plant extracts equivalent to $1000 \mu \mathrm{g}$ was dissolved in ethanol and were applied to sterile paper discs (6 $\mathrm{mm}$ diameter, Cartridge Susceptibility Discs, MAST DIAGNOSTICS, Mast Group Ltd., Merseyside, UK). The solvent was allowed to evaporate from filters deposited on 96-well plates at room temperature. The discs were then placed on the surface of the inoculated agar plates. Plates were then incubated for $24 \mathrm{~h}$ at $37^{\circ} \mathrm{C}$ (Jeio Tech Shaker, SI-300, Gasan-Dong, Geumcheon-Gu, Seoul, Korea). Ampicillin (50, 100 and $500 \mu \mathrm{g} / \mathrm{ml}$ ) was used as the positive control for antibacterial activity. Zones of inhibition were measured in $\mathrm{mm}$ after $24 \mathrm{~h}$ of growth. The experiment was performed in quadruplicate.

\section{Determination of minimum inhibitory concentration (MICs) and minimum bactericidal concentrations (MBC) and minimum fungicidal concentrations (MFC)}

The microplate method was used to determine the MIC values for plant extracts with antibacterial activities. Residues of plant extracts were dissolved to $25 \mathrm{mg} / \mathrm{ml}$ using the extracting solvent ethanol. All extracts were tested at $1000 \mu \mathrm{g} / \mathrm{ml}$ and serially diluted two-fold to 0.38 $\mu \mathrm{g} / \mathrm{ml}$ in a $96-$ multiwell polystyrene flat-bottomed microplate (SIGMAALDRICH, St. Louis, MO, USA) after which $100 \mu \mathrm{l}\left(1 \times 10^{6} \mathrm{CFU} / \mathrm{ml}\right)$ of bacteria was added to each well. Ampicillin was added as reference in each assay. Extract-free solution was used as the negative control. Preincubation absorbance values were read from an EL 340 microplate reader (BIO-TEKTM INSTRUMENTS, Winooski, VT, USA). The microplates were then incubated overnight at $37^{\circ} \mathrm{C}$ and absorbance values were read after $24 \mathrm{~h}$. MIC values were recorded as the minimum concentration of the extract that completely inhibited growth of bacteria. The experiment was performed in duplicate. Bacterial cells from the MIC test plate were sub-cultured on solid nutrient agar by making streaks on the surface of the agar. The petri dishes were incubated overnight at $37^{\circ} \mathrm{C}$ and the MBCs were determined after 24 h. Petri dishes that did not show growth were considered to be the $\mathrm{MBC}$ for the extract or drug used. The experiment was carried out in duplicate.

\section{Administration of phenobarbitone to animals}

The study was approved by the University of Zimbabwe, College 
of Health Science Ethics Committee (UZCHSEC) and approval of use of animals was obtained from the Ministry of Agriculture of Zimbabwe. The $\mathrm{S} 9$ metabolites were prepared using fractions from rat livers of animals in which drug metabolizing enzyme induction had been done in vivo using phenobarbitone at $30 \mathrm{mg} / \mathrm{kg}$ body weight. Ten weeks-old male Sprague-Dawley rats were acquired from the Animal House (University of Zimbabwe, Harare, Zimbabwe). The rats were maintained under controlled temperature of $25^{\circ} \mathrm{C}, 12 \mathrm{~h}$ light $/ 12 \mathrm{~h}$ dark conditions for one week before the start of the experiments. The animals were provided with water and food ad libitum. Animals were maintained and handled according to the recommendations of the good laboratory practices and animal handling $(\mathrm{NIH})$ guidance for the care and use of laboratory animals, Publication No. 85-23, (1985). Rats were divided into two groups; one group received a dose of phenobarbitone a known drug metabolizing enzyme inducer while the other Group received normal saline and this served as the control group. Each animal received a dose of $60 \mathrm{mg} / \mathrm{kg}$ body weight of phenobarbitone and animals in the control group each animal received a corresponding volume of normal saline. The animals were dosed by oral gastric lavage. This was performed for three consecutive days and the animals were then starved and sacrificed by cervical dislocation.

\section{Preparation of S9 fraction from rat livers}

Perfusion of animals was done in situ using normal saline to remove blood from the organs. Livers of the animals were blotted and collected into labeled containers, weighed, cut into smaller pieces and homogenized in a total amount of three times volume of $50 \mathrm{mM}$ Tris-HCL buffer ( $\mathrm{pH}$ 7.4) containing $0.154 \mathrm{M}$ potassium chloride. Homogenization was done using a motor driven Potter Elvehjem homogenizer type R2R (Heidolph Elektro KG, Kelheim, Germany). Homogenates were centrifuged at $10000 \times \mathrm{g}$ at $4^{\circ} \mathrm{C}$ for 15 minutes using a Beckman Optima LE-80K ultracentrifuge (BECKMAN INSTRUMENTS INC., California, USA). The S9 fractions were stored at $-32^{\circ} \mathrm{C}$. Protein determination was done using Lowry assay as modified by B.G Lake (1987) using bovine serum albumin as the standard.

\section{Preparation of plant extracts metabolites using rat liver S9 fractions}

Concentrations of $1 \mathrm{mg} / \mathrm{ml}, 0.5 \mathrm{mg} / \mathrm{ml}$ and $0 \mathrm{mg} / \mathrm{ml}$ of Combretum zeyheri extract were prepared in $5 \mathrm{ml}$ of buffer or ethanol solution. Incubation of Combretum zeyheri extracts was carried out in $3 \mathrm{ml}$ total volume with rat liver S9 fractions supplemented with reduced glutathione $(\mathrm{GSH})$, reduced nicotinamide adenine dinucleotide phosphate (NADPH) and uridine dipshospate glucuronic acid (UDPGA). These are cofactors required for the activity of the major drug metabolizing enzymes, glutathione transferases (GSTs), cytochrome P450 (CYP) and UDP- $\alpha$-D-glucuronsyltransferase (UDPGTase) respectively. Extracts at different concentrations (1 mg/ $\mathrm{ml}, 0.5 \mathrm{mg} / \mathrm{ml}, 0 \mathrm{mg} / \mathrm{ml}$ ) in $10 \mathrm{mM}$ Tris-HCl buffer ( $\mathrm{pH} 7.4)$ containing $1 \mathrm{mM}$ EDTA were added to rat liver $\mathrm{S} 9$ fraction with protein at $1 \mathrm{mg} /$ $\mathrm{ml}$. Un-supplemented S9 fractions were used as control. Test-tubes were kept in a water bath at $37^{\circ} \mathrm{C}$ and termination of enzymatic activity was done at times 0 minutes, 30 minutes and 60 minutes by adding $1.5 \mathrm{mls}$ of acetone and mixing to terminate the reaction. Extraction of metabolites was performed using ethyl acetate. A volume of $2 \mathrm{ml}$ of mixture in which enzymatic activity had been terminated was added into a test-tube and an equal volume of ethyl acetate was added. The mixture was mixed by vortexing, allowed to separate into two distinct layers and a volume of $1 \mathrm{ml}$ of the upper aqueous layer was taken and stored in $1.5 \mathrm{~mL}$ microtubes tubes at $-32^{\circ} \mathrm{C}$. Samples designated A-E were $S 9$ fractions from control group administered with normal saline. Samples designated F-J were S9 fractions from the group administered with phenobarbitone.

\section{Effects of C. zeyheri metabolites on growth of Candida albicans}

The effects of C. zeyheri metabolites were investigated by incubating Candida albicans and the metabolites in 96-well microplates in a total volume of $300 \mu \mathrm{l}$. To each well, $280 \mu \mathrm{l}$ of the broth inoculated with $C$. albicans $\left(1 \times 10^{6} \mathrm{CFU} / \mathrm{ml}\right)$ was added and $20 \mu \mathrm{l}$ of the metabolites were also added. For the positive control, $20 \mu \mathrm{l}$ of ketoconazole at $50 \mu \mathrm{g} /$ $\mathrm{ml}, 100 \mu \mathrm{g} / \mathrm{ml}$ and $500 \mu \mathrm{g} / \mathrm{ml}$ were used in place of metabolites. The negative control had the C. albicans alone in broth. The plates were incubated for 24 hours at $37^{\circ} \mathrm{C}$ in a Lab-Companion incubator (SI300 Incubated shaker, Jeiotech, Korea). Thereafter $50 \mathrm{uL}$ was taken and plated on SDA petri dishes and cells allowed to grow overnight at $37^{\circ} \mathrm{C}$ and colonies were counted for each plate after another 24 hours.

\section{Phytochemical screening and fractionation of C. zeyheri ethanolic extract}

In our previous work, the leaves of $C$. zeyheri were evaluated qualitatively and quantitatively for the determination of major phytoconstituents namely; alkaloids, flavonoids, tannins, saponins and cardiac glycosides [22]. Different constituents of the ethanolic extract of $C$. zeyheri were separated according to their polarity by solventsolvent partitioning using petroleum ether, chloroform, ethyl acetate and butanol. Separation was done in order of increasing polarity, the less polar compounds were separated first with petroleum ether and the more polar compounds were separated last with butanol. All the five fractions obtained by solvent-solvent partitioning were tested for their antifungal activity against $C$. albicans. The ethyl acetate fraction was found to have the most activity and so its constituents were further separated by SEPHADEX LH-20 gel column chromatography until an active fraction which was eluted as fraction number 3 was produced and is referred to as fraction 3 in this paper.

\section{Effects of plant extracts on Rhodamine 6G uptake in fungi and bacteria}

Bacterial and fungal were cultured overnight in Luria Bertani(LB) and Sabouraud dextrose broth(SDB) respectively, at $37^{\circ} \mathrm{C}$ at $110 \mathrm{rpm}$ with shaking. After 24 hours cells were centrifuged using a Rotofix 32 centrifuge (HETTICH ZENTRIFUGEN, Tuttlingen, Germany) at 4000 rpm for $5 \mathrm{~min}$ and washed twice with phosphate buffered saline (PBS) ( $\mathrm{pH}$ 7.2). Cells were centrifuged again and re-suspended at $40 \mathrm{mg} / \mathrm{ml}$ in PBS containing $10 \mathrm{mM}$ sodium azide $\left(\mathrm{NaN}_{3}\right)$. R6G was added to a final concentration of $10 \mu \mathrm{M}$ and cells placed in an incubator for 1 h. Cells were then divided into two aliquots, tube A and tube B. Cells were centrifuged for $5 \mathrm{~min}$ at $4000 \mathrm{rpm}$ and those from tube A were resuspended in PBS containing $1 \mathrm{M}$ glucose while the cells in the tube $\mathrm{B}$ were re-suspended in PBS alone. The plant extract, flavonoids or fraction 3 were added to the cells containing glucose to a final concentration of $61 \mu \mathrm{g} / \mathrm{ml}$. Reserpine at a final concentration of $100 \mu \mathrm{M}$ was used as a standard inhibitor. Both tubes were then placed in an incubator with agitation for $30 \mathrm{~min}$ at $37^{\circ} \mathrm{C}$. Cells were centrifuged and the supernatant was discarded. The remaining pellet was re-suspended in $0.1 \mathrm{M}$ glycine $\mathrm{HCl}, \mathrm{pH} 3$ and placed in a shaking incubator overnight. After $24 \mathrm{~h}$, cells were centrifuged for $10 \mathrm{~min}$ at $4000 \mathrm{rpm}$ and the supernatant collected for measuring absorbance at $527 \mathrm{~nm}$ using a Shimadzu UV/VIS UV1601 spectrophotometer (Shimadzu, Kyoto, Japan). 
Citation: Masengu C, Zimba F, Mangoyi R, Mukanganyama S (2014) Inhibitory Activity of Combretum zeyheri and its S9 Metabolites against Escherichia coli, Bacillus subtilis and Candida albicans. J Microb Biochem Technol 6: 228-235. doi:10.4172/1948-5948.1000149

\section{Statistical analysis}

A comparison of the efflux activity of the samples with the standard efflux inhibitor, reserpine was evaluated by applying one way ANOVA Dunnet's Multiple Comparison Test. All values are expressed as the mean \pm standard deviation and $\mathrm{P}<0.05$ values or less were considered to indicate statistically significant differences. Numerical data were analyzed using Graphpad $^{\text {tw }}$ version 4 for Windows (GRAPHPAD SOFTWARE INC., San Diego, California, USA).

\section{Results}

\section{Inhibition of bacterial growth by extracts from C. zeyheri}

The effects of C. zeyheri extract on the growth of E. coli and B. subtilis is shown by growth inhibition parameters (Table 1). The plant extract inhibited both the bacteria species with $B$. subtilis being inhibited the most. The methanol extract had a lesser inhibition potency as compared to the water extract. Although both plant extracts inhibited the bacterial species, the effects were less than that of ampicillin as no MIC and MBCs with the plant extracts were obtained.

\section{Effects of phenobarbitone on male Sprague-dawley rats}

When rats were administered with phenobarbitone, relatively higher liver weights were obtained compared to those obtained with animals dosed with normal saline (Figure 1). When protein content was determined, lower values were obtained for the PB group as compared to those of saline group. When the body weights of the animals were determined prior to sacrifice, animals from the PB group generally had higher body weight relative to the body weights compared to those obtained from animals given saline. The liver to body weight ratio showed higher values for animal's administered with phenobarbitone.

\section{Effects of C. zeyheri S9 metabolites on growth of Candida albicans}

It was important to determine if the previously reported effects of C. zeyheri on C. albicans could be due to the parent compounds or possibly metabolites. In this regards the effects of C. zeyheri mammalian S9 products from rats were investigated on the growth of $C$. albicans. When the S9 metabolites from untreated rats were used, there was a general decrease in number of colonies with time of incubation, and differences were also noted between the saline group and the PB-treated group. Generally the numbers of colonies were less in Candida exposed to S9 metabolites from rats pre-treated with phenobarbitone (Figure 2) suggesting that the metabolites from the extract had a higher antifungal effect than in the saline group. An increase in the number of colonies for the PB group was obtained after 60 minutes of incubation whilst, at the same particular concentration of extract, metabolites obtained at 30 minutes inhibited growth of C. albicans (Figure 3). There were no much variations in number of colonies obtained with respect to either time or concentration of extract. The corresponding saline groups gave significant decrease in the numbers of colonies with respect to both time and extract concentration.

\begin{tabular}{|c|c|c|c|c|c|}
\hline Bacteria & $\begin{array}{c}\text { Methanol } \\
\text { extract }\end{array}$ & $\begin{array}{c}\text { Water } \\
\text { extract }\end{array}$ & Ampicillin & Water & Methanol \\
\hline E. coli & $10 \pm 0.5$ & $18.8 \pm 0.7$ & $18.5 \pm 0.8(\mathrm{MIC} 0.125 \mathrm{MBC} 0.125)$ & 6 & 6 \\
\hline B. subtilis & $10 \pm 0.5$ & $18.5 \pm 0.5$ & $37 \pm 0.75(\mathrm{MIC}=0.004 \mathrm{MBC}=0.5)$ & 6 & 6 \\
\hline
\end{tabular}

The minimum inhibitory concentration and minimum bactericidal concentrations are in $\mathrm{mg} / \mathrm{ml}$. Water and methanol was used as the negative controls as they were used to dissolve the samples. The values are a mean $+S D$ for $n=8$.

Table 1: Zones of inhibition of the C. zeyheri plant extracts on $E$. coli and B. subtilis.
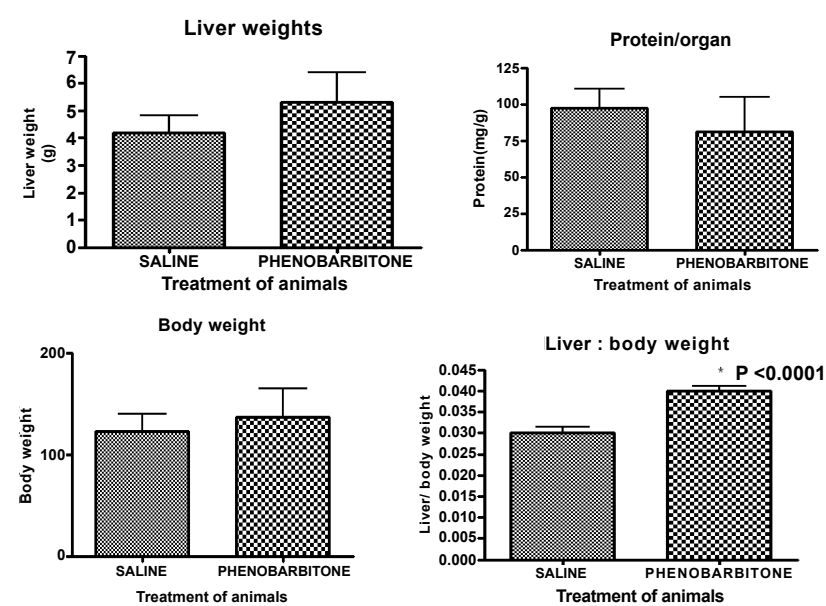

Figure 1: Effects of phenobarbitone on physiological and biochemical parameters of Sprague-Dawley rats. Generally an increase in liver weights and a decrease in protein concentration for the rats administered with phenobarbitone were observed.

${ }^{*} \mathrm{P}<0.0001$ for $\mathrm{N}=5$

Values are mean $\pm \mathrm{SD}$ for $\mathrm{N}=5$ (a) saline at $t=0$

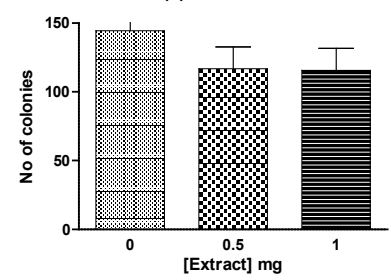

(b) saline at $t=30$

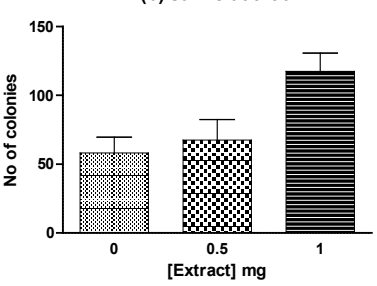

(c) saline at $\mathrm{t}=60$

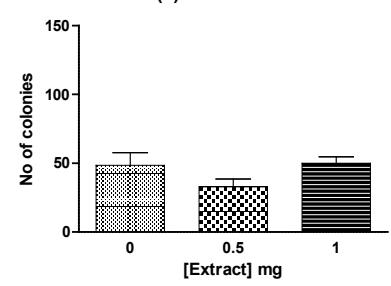

(d) $\mathrm{Pb}$ at $\mathrm{t}=0$

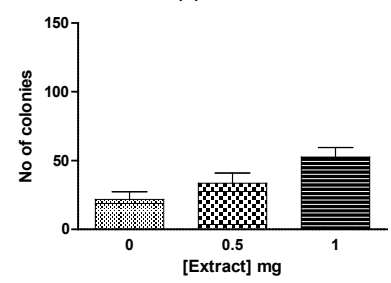

(e) $\mathrm{Pb}$ at $\mathrm{t}=\mathbf{3 0}$

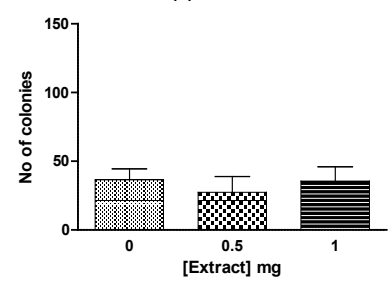

(f) $\mathrm{Pb}$ at $\mathrm{t}=60$

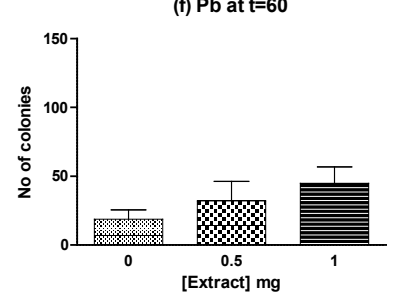

Figure 2: The effects of $C$. zeyheri extract $S 9$ metabolites on the number of colonies of Candida albicans as a function of time of incubation. A general decrease in number of colonies of $C$. albicans with time of incubation was observed when the S9 metabolites from untreated rats were incubated with C. zeyheri. The numbers of colonies were less in Candida exposed to S9 metabolites from rats pre-treated with phenobarbitone.

Values are mean \pm SD for $\mathrm{N}=3$ 
Saline and phenobarbitone at $0 \mathrm{mg} / \mathrm{ml}$

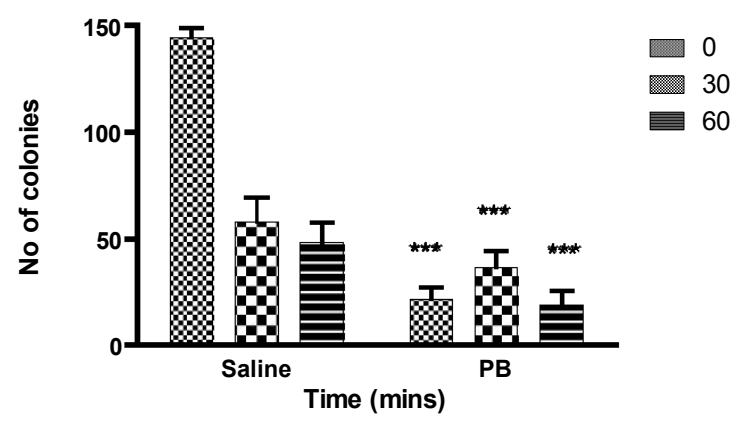

Saline and phenobarbitone at conc. $0.5 \mathrm{mg} / \mathrm{ml}$

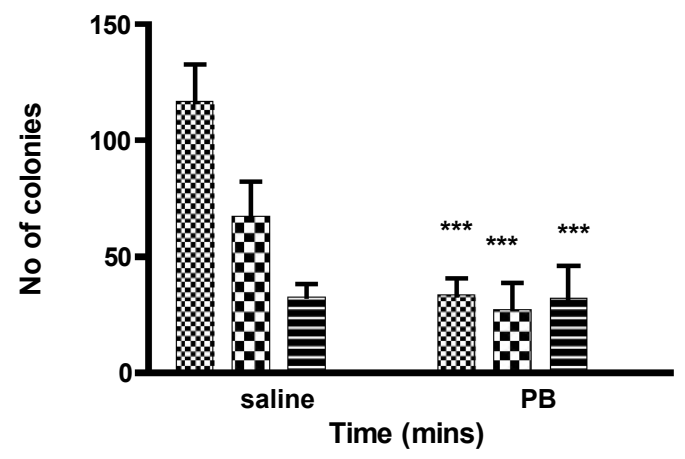

Saline and phenobarbitone at conc. $1 \mathrm{mg} / \mathrm{ml}$

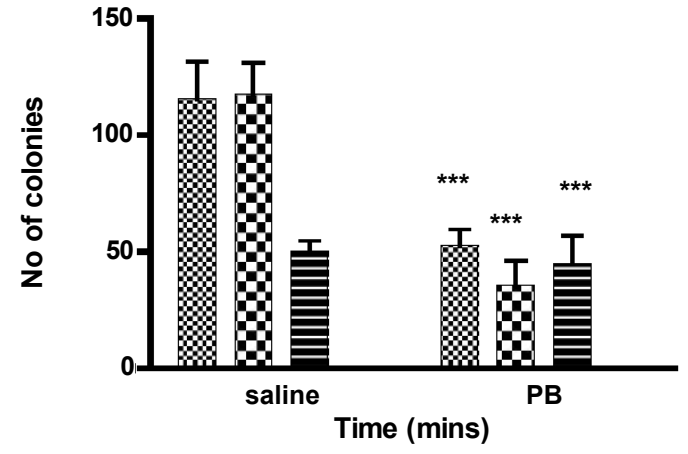

Figure 3: The effects of S9 metabolites of $C$. zeyheri on the number of colonies as a function of concentration of the extract and time of incubation. There were no much variations in number of colonies obtained with respect to either time or concentration of extract.

\section{Effect of C. zeyheri on Rhodamine 6G efflux in candida and} bacterial cells

The effects of $C$. zeyheri on the efflux of rhodhamine $6 \mathrm{G}$ was investigated in E. coli and B. subtilis (Figure 4) and C. albicans (Figure 5). Bacterial cells which were exposed to glucose had the least amount of the dye left in the cells, thus, indicating active efflux with glucose serving as a source of energy. Cells exposed to glucose and the plant extract retained a higher amount of dye, thus, indicating the inhibition of the efflux of the dye from the cells. Reserpine, a standard inhibitor efflux inhibitor showed the inhibition of drug efflux (Figure 4). The plant extracts showed the same extent of inhibition in both bacteria species although there was highest inhibition of efflux pumps in E. coli as compared to B. subtilis. There was a difference in the accumulation of R6G in B. subtilis and E. coli cells upon the addition of glucose. Whilst the levels of R6G were reduced in B. subtilis, they were increased in E. coli. When the plant extracts and reserpine were added the concentration of dye inside cells increased to an extent more than for glucose. This suggests a greater inhibition of efflux pumps by the extracts and reserpine. The effects flavonoids and fraction 3 on the accumulation of R6G in C. albicans showed that these constituents were also inhibitors of active transport (Figure 5). For Candida albicans, the results show that whilst there was increase in accumulation of R6G in the presence of extract, reserpine and flavonoids, fraction 3 in contrast enhanced the efflux of rhodhamine $6 \mathrm{G}$ from the cells.

\section{Discussion}

Combretum zeyheri is an important medicinal plant used throughout Africa [23]. Whilst most of the information on the use of this plant is based on ethnomedicine, this study sake to establish and scientifically validate the potential of the leaf extracts of C. zeyheri as antimicrobial compounds against bacteria and fungi. The qualitative agar diffusion method was used to establish antibacterial activity of compounds. Then MIC determination and MBC determination was used to quantitatively establish the potency of the extracts. Another way by which bacteria become resistant to antibiotics is through pumping the drug out of cells, keeping its concentration below therapeutic levels
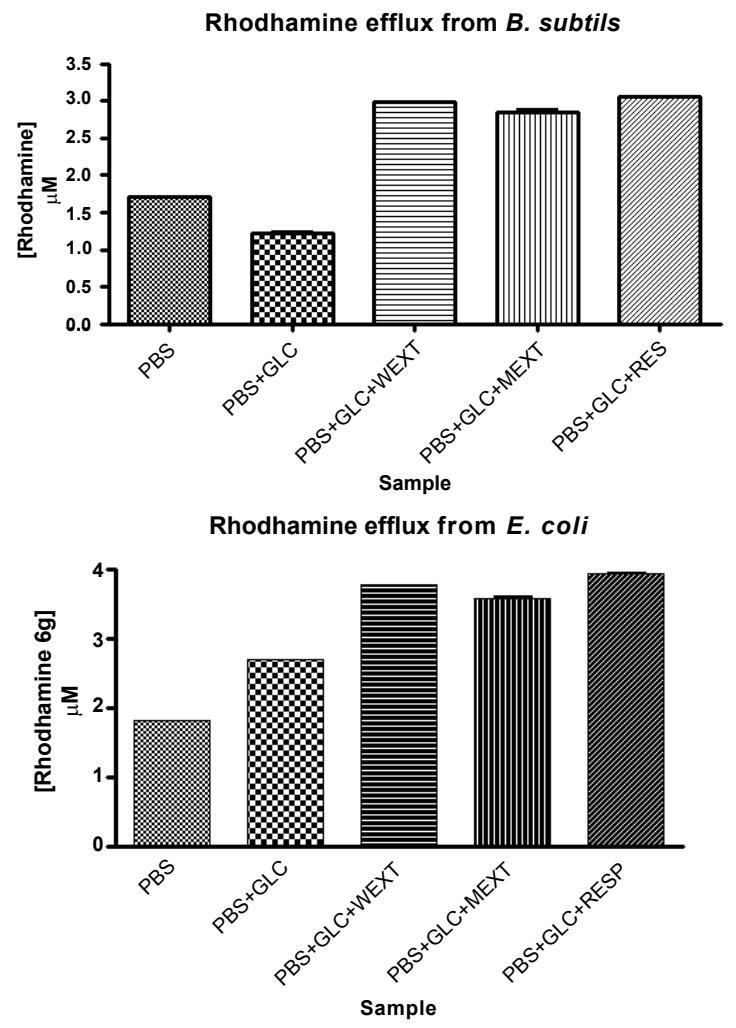

Figure 4: The effects of $C$. zeyheri extract on drug efflux from $B$. subtilis (A) and $E$. coli

(B) using rhodamine 6G. Bacterial cells which were exposed to glucose had the least amount of the dye left in the cells, thus, indicating active efflux with glucose serving as a source of energy. Cells exposed to glucose and the plant extract retained a higher amount of dye, thus, indicating the inhibition of the efflux of the dye from the cells. Reserpine, a standard inhibitor efflux inhibitor showed the inhibition of drug efflux. 


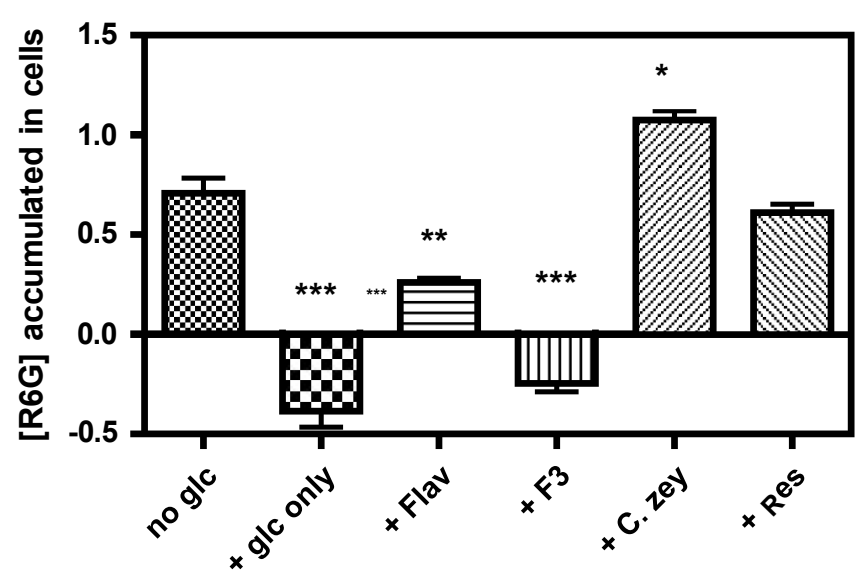

Figure 5: The effects of $C$. zeyheri on the accumulation of R6G in C. albicans. Cells were exposed to $C$. zeyheri extract, fraction 3(F3), flavanoids (Flav) or the standard inhibitor reserpine (Res). Bacterial cells which were exposed to glucose had the least amount of the dye left in the cells, thus, indicating active efflux with glucose serving as a source of energy. Cells exposed to glucose and fraction 3 and flavonoids had a higher amount of dye, thus, indicating the inhibition of the efflux of the dye from the cells. Reserpine, a standard inhibitor efflux inhibitor showed the inhibition of drug efflux.

[24]. If a drug is able to inhibit the efflux drug channels, it has a potential for maintaining the levels of other antibiotics within therapeutic levels if taken in combination with them [25]. Hence, the effects of plant extracts on efflux pumps were also accessed as inhibitors of these pumps. There are several models that can be used to evaluate efflux pump inhibitors and these include ethidium bromide efflux, berberine efflux, ciprofloxacin efflux and rhodamine $6 \mathrm{G}$ efflux [26], but this study focused only on efflux of rhodamine $6 \mathrm{G}$. Rhodamine $6 \mathrm{G}$ is a dye that can be pumped into and out of cells by pumps on cell membranes [27]. By analyzing the amount of dye left in the cells after exposing them to the plant extract one is able to deduce the activity of the efflux pumps assuming that the major route the dye uses into and out of the cell is via active transport by transmembrane pumps [28]. The effects of the natural plant metabolites of $C$. zeyheri were assessed on C. albicans. The basis for the investigation was also to determine how effective the metabolites were as potential antifungal against Candida.

For the growth inhibition antibacterial tests (Table 1), the plant extracts and ampicillin were able to diffuse from the disk into the agar gel and form zones of inhibition. The water extract had a greater zone of inhibition as compared to the methanol extract of C. zeyheri suggesting that the compounds in the water extract were able to diffuse and cover a greater zone of inhibition causing a greater inhibition. The plant extracts of C. zeyheri had antibacterial effects and this finding supports the use of $C$. zeyheri traditionally to cure infectious ailments such as coughs and diarrhea $[29,30]$. The plant showed more antimicrobial activity for B. subtilis as compared to E. coli since B. subtilis is a gram positive bacterium whilst $E$. coli is a gram negative bacterium.

The lower the MIC value the more active the extract. There are some compounds that only have a bacteriostatic effect only and do not cause bactericidal effects [23]. The plant extracts did not show both the MIC and the MBC values in the concentration range used of $0.002-1 \mathrm{mg} /$ $\mathrm{ml}$ whilst ampicillin was able to give an MIC and MBC value indicating that the plant extracts were more bacteriostatic than bactericidal as compared to ampicillin. Therefore, C. zeyheri extracts seem to be of less importance when it comes to treating bacterial infections. However, the activation of the chemicals in the extracts by mammalian drug metabolizing enzymes to active species with antibacterial effects should not be ruled out as a mechanism of action of the C. zeyheri.

Energy-dependent drug efflux is a major mechanism of resistance in microorganisms [31]. In these circumstances, a successful clinical outcome may be obtained by using a higher dose of the antibiotic. Another potential therapeutic strategy is to obtain and utilize antibiotics that inhibit the efflux pumps, thereby, counteracting the pumps ability to lower intracellular antibacterial concentrations to sub-inhibitory levels. The effects of extracts and phyto-constituents such as flavonoids from C. zeyheri were investigated to determine their potential as inhibitors of drug efflux in bacteria and fungi. When the medium containing these cells was supplemented with glucose, the glucose provided the energy to the efflux pumps, thus, activating these to pump out their substrates including rhodamine $6 \mathrm{G}$. When the plant extracts were added to this mixture, the amount of dye that remained in the cells increased as compared to the cells without glucose suggesting that the plant extracts inhibited the efflux pumps (Figures 4 and 5). This can support the traditional use of $C$. zeyheri with other plants, because extracts from this plant may be inhibiting drug efflux pumps in the pathogens and, thus, increasing intracellular concentrations of other plant phyto-constituents with bactericidal activity and leading to cell death. There was a greater basal efflux activity in B. subtilis as compared to $E$. coli and this could also be due differences in cell wall structutres as $B$. subtilis has only one outer membrane which makes it not able to effectively the control of substances living and entering the cell. In both bacterial species, both the water extract and methanol extracts had similar efflux inhibition suggesting that there might be a similarity in the compounds they extracted (Figure 4). Differences were, however, noted between the effects of glucose in the two bacterial species (Figure 4). Under normal circumstances the presence of glucose was supposed to cause a decrease of the amount of dye left in the cells. This would be as a result of glucose supplying energy to the efflux pumps to activate them. The pumps would then pump the dye out resulting in reduced concentration of dye inside cells. This suggest that the glucose might be having a different effect on drug efflux pumps on the E. coli membrane which could result in inhibition or the Gram-negative architecture of the cell wall of $E$. coli simply serves as a barrier to the transport of substances across the cell membrane [31]. The inhibition caused by the plant extracts in both bacterial species might be due to the extracts acting as pseudosubstrates being pumped out in place of the dye $[32,33]$. Another mechanism by which inhibition could have occurred is through the formation of stable complexes such as binding by quinones. The complexes which would have been formed by the plant extracts and the efflux pumps might result in alteration of the protein structure of the efflux pumps so that they are no longer able to pump compounds out of the cell.

Combretum zeyheri has been shown to have antifungal effects against C. albicans with an MIC of $0.08 \mathrm{mg} / \mathrm{ml}$ and an MFC of 0.31 $\mathrm{mg} / \mathrm{ml}$ [11]. It was also shown that extracts of C. zeyheri were able to inhibit drug efflux activity when ciprofloxacin was used as the probe drug [11]. Rhodhamine $6 \mathrm{G}$ has been identified as a specific substrate for drug efflux mediated by $\mathrm{ABC}$ proteins in Candida albicans [34]. Therefore, it was necessary to determine the drug efflux activity using a specific efflux substrate for the ATP binding cassette transporters from Candida albicans, CDR1 and CDR2 pumps. Cdr1p and Cdr2p are major ATP-dependent drug efflux pump proteins, which play a key role in azole resistance of Candida species [35]. Candida albicans accumulated high concentrations of Rhodhamine $6 \mathrm{G}$ in the presence of extracts from C. zeyheri (Figure 5) and, this, confirms the inhibition of ABC-type drug efflux pumps in this yeast by the plant extract. 
Citation: Masengu C, Zimba F, Mangoyi R, Mukanganyama S (2014) Inhibitory Activity of Combretum zeyheri and its S9 Metabolites against Escherichia coli, Bacillus subtilis and Candida albicans. J Microb Biochem Technol 6: 228-235. doi:10.4172/1948-5948.1000149

The liver is the main site of drug metabolism and, therefore, in vitro studies are predominantly focused on using hepatocytes or subcellular hepatic fractions such as the endoplasmic reticulum (microsomes) or the S9 fractions. The S9 fraction or postmitochondrial supernatant fraction consists of microsomes and cytosol and it contains a wide variety of both phase I and phase II enzymes. The S9 can be supplemented with cofactors such as UDPGA, and glutathione to investigate Phase II metabolic pathways. A liver microsomal preparation, rich in cytochrome P450 activity, simulates passage of a drug or plant extract through the body. Generally, the metabolic activity of S9 fraction is enhanced by in vivo induction. Nevertheless, these systems have shortfalls rendered by the complexity of metabolic pathways involved in generation of metabolites by different phase 1 and phase 2 enzymes. The S9 fraction supplemented with NADPH, UDPGA and GSH would give metabolites from the enzymes cytochrome P450, uridine di-phosphate glucuronosyl transferases and glutathione transferases respectively. The aim of this part of the study was to determine if the antifungal effects of C. zeyheri were as a result of the parent chemical species in the extract or a result of metabolic products that arise as a result of drug metabolizing activity in the body. A decline in number of colonies was noted with increase in time of incubation of $S 9$ fraction with plant extract for the saline -dosed group even without the plant extract (Figure 2). This could imply that something inherent to the S9 fraction was having an effect on growth of Candida albicans. At $0.5 \mathrm{mg} / \mathrm{ml}$ concentration of extract, growth inhibition increased when metabolites were obtained after 30 minutes of incubation compared with growth noted at time zero. However, there was no significant change in extent of inhibition of growth of $C$. albicans with metabolites obtained after 30 minutes and those obtained after 60 minutes of incubation. This could mean that metabolites were formed after 30 minutes and they had an effect on growth of C. albicans. The insignificant change in growth inhibition between time 30 minutes and 60 minutes of incubation of the metabolites and the Candida albicans could be due metabolic enzyme saturation in the production of the metabolites such that the numbers of metabolites between 30 and 60 minutes were the same. A significant decrease in number of colonies and thus, growth of C. albicans, with extract concentration of $1 \mathrm{mg} /$ $\mathrm{ml}$, after 1 hour of incubation compared to what was noted at time 30 minutes (Figure 2). Increased incubation time in the presence of more substrate would give more metabolites that exerted an inhibitory effect on growth of C. albicans. In the group given phenobarbitone, an inducer of drug metabolizing enzymes, the un-supplemented $S 9$ fractions in the absence of plant extract showed low numbers of colonies that were produced compared to the corresponding saline group S9 fractions. This implies that the $\mathrm{PB}$ induced some proteins that metabolized the extract and produced products that were part of the S9 fraction, that were responsible for inhibition of growth of Candida albicans. A significant fall in number of colonies at $1 \mathrm{mg} / \mathrm{ml}$ was noted after metabolism had been allowed to take place for 30 minutes (Figure 3 ). Increased enzymatic activity due to in vivo enzyme induction resulted in more metabolites being produced within a short period of time. Considering the number of colonies with respect to time point at which metabolites were extracted, the S9 fractions from the supplemented phenobarbitone dosed group generally had lesser number of colonies (Figure 3). It is possible that due to increased enzymatic activity in the liver samples from animals dosed with the typical enzyme inducerphenobarbitone, more metabolites of the plant extract were being produced and they could be exhibiting inhibition properties on growth of $C$. albicans. Amongst the phenobarbitone group, at each particular concentration of $0 \mathrm{mg} / \mathrm{ml}, 0.5 \mathrm{mg} / \mathrm{ml}$ and $1 \mathrm{mg} / \mathrm{ml}$, there was no significant difference in terms of number of colonies obtained with metabolites extracted at time intervals 0 minutes, 30 minutes and 60 minutes (Figure 3). The supplemented S9 fractions from the saline dosed group showed a significant decrease in number of colonies obtained with time. This could be due to the fact that the for this group, the basal enzyme expression produces lower enzyme activity which require more time for metabolism of a particular amount of substrate since enzyme saturation possibly occurs. Therefore, increase in time span over which metabolism occurs allows observation of the decline in the number of colonies with increased amount of metabolites, thus, possibly suggesting that metabolites of the aqueous extract of $C$. zeyheri possibly have an effect on growth of Candida albicans. Comparison of the results in the un-supplemented $S 9$ fraction versus supplemented S9 fraction showed no difference on antifungal effects by the C. zeyheri on C. albicans. It is possible that before supplementing with the exogenous cofactors, the S9 fractions already had appreciable amounts of the cofactors to sustain enzymatic activity to a certain extent, thus, showing the lack of differences between the two treatments.

In conclusion, C. zeyheri exhibits both antifungal and antibacterial effects with respect to C. albicans, B. subtilis and E. coli. These effects may be mediated via direct inhibition of ATP-dependent drug efflux systems in these microbes. Our results also show that the mammalian metabolism of the C. zeyheri extracts produces metabolites that have antifungal effects on C. albicans. Further work needs to be carried out to determine the identity of the metabolites as well as determine the effects of the metabolites on bacteria.

\section{Acknowledgements}

This study was sponsored by the International Foundation in Sciences (IFS) Stockholm, Sweden; Grant Number F/3413-03. Support from the International Program in the Chemical Sciences (IPICS: ZIM01), Uppsala University, Uppsala, Sweden and the Reaserch Board, (RB72/2011) University of Zimbabwe is also acknowledged.

\section{References}

1. Greenwood D, Slack RCB, Pentherer JF (1992) Medical microbiology. A guide to microbial infections: pathogenesis, immunity, laboratory diagnosis and control. (14thedn), Churchhill Livingstone, London.

2. Patel DMS (2009) Pharmacokinetics of Ceftriaxone in skin following iontophoretic administration in a rabbit model. Long Island University, the Brooklyn Center.

3. Anderson JB (2005) Evolution of antifungal-drug resistance: mechanisms and pathogen fitness. Nat Rev Microbiol 3: 547-556.

4. Stavri M, Piddock LJ, Gibbons S (2007) Bacterial efflux pump inhibitors from natural sources. J Antimicrob Chemother 59: 1247-1260.

5. Jin J, Zhang JY, Guo N, Sheng H, Li L, et al. (2010) Farnesol, a potential efflux pump inhibitor in Mycobacterium smegmatis. Molecules 15: 7750-7762.

6. Cowan MM (1999) Plant products as antimicrobial agents. Clin Microbiol Rev 12: $564-582$

7. Dar SA, Yousuf AR, Ganai FA, Sharma P, Kumar N, et al. (2012) Bioassay guided isolation and identification of anti-inflammatory and anti-microbial compounds from Urtica dioica L. (Urticaceae) leaves. African Journal of Biotech 11: $12910-12920$.

8. Fyhrquist $P$ (2007) Traditional medicinal uses and biological activities of some plant extracts of African Combretum Loefl, Terminalia L. and Pteleopsis Engl. species (Combretaceae)

9. Masoko P, Eloff JN (2006) Bioautography indicates the multiplicity of antifungal compounds from twenty-four Southern African Combretum species (Combretaceae). African Journal of Biotech 5: 1625-1647.

10. Palgrave KC (2002) Trees of Southern Africa. Struik Publishers, Cape Town, South Africa

11. Mangoyi R, Mukanganyama S (2011) In vitro antifungal activities of some 
Citation: Masengu C, Zimba F, Mangoyi R, Mukanganyama S (2014) Inhibitory Activity of Combretum zeyheri and its S9 Metabolites against Escherichia coli, Bacillus subtilis and Candida albicans. J Microb Biochem Technol 6: 228-235. doi:10.4172/1948-5948.1000149

selected plants from Zimbabwean against Candida albicans and Candida krusei. AJPSB 3: 8-14

12. Bii CC, Kangogo MC, Revathi G, Wanyoike MW (2009) Genotypes of Candida albicans from clinical sources in Nairobi Kenya. AJMR 3: 475-477.

13. Cruz MC, Santos PO, Barbosa AM Jr, de Mélo DL, Alviano CS, et al. (2007) Antifungal activity of Brazilian medicinal plants involved in popular treatment of mycoses. J Ethnopharmacol 111: 409-412.

14. Cannon RD, Lamping E, Holmes AR, Niimi K, Baret PV, et al. (2009) Effluxmediated antifungal drug resistance. Clin Microbiol Rev 22: 291-321, Table of Contents.

15. Pitout JDD (2012) Extraintestinal pathogenic Escherichia Coli: a combination of virulence with antibiotic resistance. Frontier in microbiol 3: 1-7.

16. Srivastava A, Kumar L (2012) Bacterial contaminates in drinking water of Palamuru villages. International Journal of Biology, Pharmacy and Allied Sciences 1: 709-717.

17. Saari HL (2004) Risk management in drug development projects Helsink University of Technology, Laboratory of Industrial Management.

18. zur Wiesch PA, Kouyos R, Engelstädter J, Regoes RR, Bonhoeffer S (2011) Population biological principles of drug-resistance evolution in infectious diseases. Lancet Infect Dis 11: 236-247.

19. Loeffler J, Stevens DA (2003) Antifungal drug resistance. Clin Infect Dis 36 S31-41.

20. Mukanganyama S, Chirisa E, Hazra B (2012) Antimycobacterial activity of diospyrin and its derivatives against Mycobacteriml aurum. Research in Pharmacy 2: 1-13.

21. Zaidan MR, Noor Rain A, Badrul AR, Adlin A, Norazah A, et al. (2005) In vitro screening of five local medicinal plants for antibacterial activity using disc diffusion method. Trop Biomed 22: 165-170.

22. Mangoyi R, Mafukidze W, Marobela K, and Mukanganyama S (2012) Antifungal Activities and Preliminary Phytochemical Investigation of Combretum Species from Zimbabwe. J Microbial Biochem Technol 4: 2.

23. Augustino S, Hall JB, Makonda FBS, Ishengoma RC (2011) Medicinal Resources of the Miombo woodlands of Urumwa, Tanzania: Plants and its uses. JMPR 5: 6352-6372.
24. Moreira MAS, de Souza EC, de Moraes CA (2004) Multidrug efflux systems in Gram-negative bacteria. Brazillian Journal of Microbiol 35: 19-28.

25. Hanušová V, Boušová I, Skálová L (2011) Possibilities to increase the effectiveness of doxorubicin in cancer cells killing. Drug Metab Rev 43: 540557.

26. Kourtesi C, Ball AR, Huang YY, Jachak SM, Vera DM, et al. (2013) Microbia efflux systems and inhibitors: approaches to drug discovery and the challenge of clinical implementation. Open Microbiol J 7: 34-52.

27. Vanden Bossche H (1997) Mechanisms of antifungal resistance. Rev lberoam Micol 14: 44-49.

28. Sanglard D, Ischer F, Monod M, Bille J (1997) Cloning of Candida albicans genes conferring resistance to azole antifungal agents: characterization of CDR2, a new multidrug ABC transporter gene. Microbiology 143: 405-416.

29. Ruffo CK (1991) A survey of medicinal plants in Tabora Region, Tanzania. In Proceedings of International Conference on Traditional Medicinal Plants.

30. Ribeiro A, Romeiras MM, Tavares J, Faria MT (2010) Ethnobotanical survey in Canhane village, district of Massingir, Mozambique: medicinal plants and traditional knowledge. J Ethnobiol Ethnomed 6: 33.

31. Van Bambeke F, Pages JM, Lee VJ (2010) Inhibitors of bacterial efflux pump as adjuvants in antibacterial therapy and diagnostic tools for detection of resistance by efflux. Frontiers in Anti-Infective Drug Discovery 1: 138-175.

32. Nelson ML (2002) Modulation of antibiotic efflux in bacteria. Current Medicinal Chemistry-Anti-infective Agents 1: 35-54.

33. De Rossi E, Aínsa JA, Riccardi G (2006) Role of mycobacterial efflux transporters in drug resistance: an unresolved question. FEMS Microbiol Rev 30: $36-52$

34. Sanglard D, Ischer F Calabrese D, Majcherczyk PA, Bille J (1999) The ATP binding cassette transporter gene CgCDR1 from Candida glabrata is involved in the resistance of clinical isolates to azole antifungal agents. Antimicrob Agents and Chemother 43: 2753-2765.

35. Kolaczkowski M, Kolaczkowska A, Motohashi N, Michalak K (2009) New throughput screening assay to reveal similarities and differences in inhibitory sensitivities of multidrug ATP-Binding cassette transporters. Antimicrob Agents and Chemother 6: 1516-1527. 